\title{
Management of a Patient with a Broken Heart Syndrome
}

\section{Nihit Mehta*}

Department of Medicine, University of New England, College of Osteopathic Medicine, USA

*Corresponding author: Nihit Mehta, Department of Medicine, University of New England College of Osteopathic Medicine, USA, Tel: +1 (207) 283-0171; E-mail: nmehta@une.edu

Received date: December 28, 2017; Accepted date: January 04, 2018; Published date: January 08, 2018

Copyright: (c) 2018 Mehta N. This is an open-access article distributed under the terms of the Creative Commons Attribution License, which permits unrestricted use, distribution, and reproduction in any medium, provided the original author and source are credited.

\section{Abstract}

- Differentiating Takotsubo's versus AMI on the basis of an Electrocardiogram

- Discuss the management of Takotsubo's with pre-existing anxiety disorder

Keywords: Cardiomyopathy; Anxiety; Coronary artery disease

\section{Case Study}

A 64-years-old female with a past medical history of Anxiety, Takotsubo's Cardiomyopathy, Diverticulitis, Coronary Artery Disease Myocardial infarction and diabetes, presented to our Emergency Room with intermittent $10 / 10$ chest pain, radiating to the left side of her chest, of 2 weeks duration. The pain was associated with nausea, abdominal pain with bowel movements and diaphoresis [1]. There was no pleuritic component associated with that the pain.

Cardiac enzyme screen, EKG and chest X-ray (Figure 1) were done in the E.R. She was started on Amlodopine, ASA, Lisinopril, Carvedilol, Nitroglycerin and Insulin and all labs returned within normal limits.

- Small LV size, LVEF estimated to be $70 \%$.

- Myxomatous Mitral valve with Chordal Systolic anterior motion. Trace Mitral regurgitation

It was discovered that the patient had stopped her Alprazolam, which had exacerbated her anxiety. This was the cause of her chest discomfort.

The patient was discharged on her home medications, and her alprazolam was tapered with the addition of an SSRI, for the management of her anxiety.

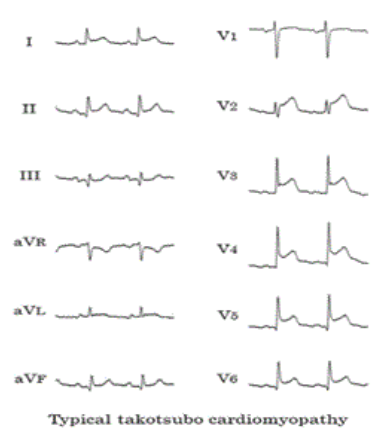

Figure 1: Typical Takotsubo cardiomyopathy.

\section{Discussion}

Takotsubo's Cardiomyopathy or broken heart syndrome is a disorder that often mimics Acute Myocardial Infarction upon presentation. Patients often present with acute chest pain, shortness of breath and EKG changes. ST elevations commonly seen in an acute MI are also characteristic of Takotsubo's. Yet, there are areas of differentiation, for instance, the EKG changes show no changes in reciprocal leads [2]. The etiology of Takotsubo's is often a topic of much debate, possible causes including, but not limited to anxiety, catecholamine release and over activation of sympathetic system. Our patient who had a pre-existing anxiety disorder, had symptoms of Takotsubo's precipitated by consecutive emotionally stressful events in her life. This is a phenomenon quite common in Takotsubo's patients.

Important towards the management of such patients with Takotsubo's, could perhaps be the persistent treatment of the underlying anxiety disorder [3]. Though our patient's event wasn't cardiac, in their case report, "Takotsubo Cardiomyopathy Precipitated by Tapering of Anxiolytic Medication", authors highlight how tapering anxiolytics possibly precipitated a woman's Takotsubo's (Figure 2).

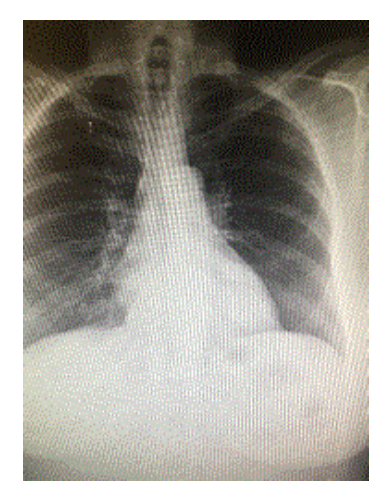

Figure 2: CXR of patient that shows no cardiomegaly or other signs of cardiac events.

\section{References}

1. Lazzeroni D, Matteo B, Paolo C, Luca M, Chiara C, et al. (2017) Anxiety disorders and stressful events in Takotsubo syndrome. J Cardiol 24. 
Citation: Mehta N (2018) Management of a Patient with a Broken Heart Syndrome. J Gen Pract (Los Angel) 6: 346. doi: $10.4172 / 2329-9126.1000346$

Page 2 of 2

2. Lafferty CJ, Tariq B, Peter OC, Adam A, Farshid D, et al. (2017) Takotsubo Cardiomyopathy Precipitated by Tapering of Anxiolytic Medication: A Case Report. Clin Med Insights Cardiol 11: 43.
3. Yasuki K, Satosi K (2014) Clinical Management of Takotsubo Cardiomyopathy. Circ J 78: 1559-1566. 